\title{
Extraction of Several Divalent Metal Picrates by 18-Crown-6 Ether Derivatives into Benzene: A Refinement of Methods for Analyzing Extraction Equilibria
}

\author{
Yoshihiro Kudo ${ }^{1}$, Yuu Takahashi ${ }^{2}$, Shoichi Katsuta ${ }^{1} \&$ Yasuyuki Takeda ${ }^{1}$ \\ ${ }^{1}$ Graduate School of Science, Chiba University, Chiba, Japan \\ ${ }^{2}$ Department of Chemistry, Faculty of Science, Chiba University, Chiba, Japan \\ Correspondence: Yoshihiro Kudo, Graduate School of Science, Chiba University, 1-33 Yayoi-cho, Inage-ku, \\ Chiba 263-8522, Japan. Tel: 81-43-290-2786. E-mail: iakudo@faculty.chiba-u.jp
}

$\begin{aligned} & \text { Received: August 1, } 2013 \quad \text { Accepted: September 17, } 2013 \quad \text { Online Published: October 17, } 2013 \\ & \text { doi:10.5539/ijc.v5n4p90 }\end{aligned} \quad$ URL: http://dx.doi.org/10.5539/ijc.v5n4p90

\begin{abstract}
Three kinds of extraction constants, $K_{\mathrm{ex}}, K_{\mathrm{ex} \pm}$, and $K_{\mathrm{ex}+}$, were evaluated from the improved model that the following three component-equilibria were added to a previously-proposed model for an overall extraction: $\mathrm{M}^{2+}$ $+\mathrm{A}^{-} \rightleftharpoons \mathrm{MA}^{+}, \mathrm{MLA}_{\mathrm{Bz}}^{+}+\mathrm{A}_{\mathrm{Bz}}^{-} \rightleftharpoons \mathrm{MLA}_{2, \mathrm{Bz}}$, and $\mathrm{A}^{-} \rightleftharpoons \mathrm{A}_{\mathrm{Bz}}^{-}$. Here, $K_{\mathrm{ex}}, K_{\mathrm{ex} \pm}$, and $K_{\mathrm{ex}+}$ were defined as $\left[\mathrm{MLA}_{2}\right]_{\mathrm{Bz}} /\left(\left[\mathrm{M}^{2+}\right][\mathrm{L}]_{\mathrm{Bz}}\left[\mathrm{A}^{-}\right]^{2}\right), \quad\left[\mathrm{MLA}^{+}\right]_{\mathrm{Bz}}\left[\mathrm{A}^{-}\right]_{\mathrm{Bz}} /\left(\left[\mathrm{M}^{2+}\right][\mathrm{L}]_{\mathrm{Bz}}\left[\mathrm{A}^{-}\right]^{2}\right)$, and $\left[\mathrm{MLA}^{+}\right]_{\mathrm{Bz}} /\left(\left[\mathrm{M}^{2+}\right]\left[\mathrm{L}_{\mathrm{Bz}}\left[\mathrm{A}^{-}\right]\right)\right.$, respectively; the subscript "Bz" denotes benzene as an organic phase. The symbols correspond to $\mathrm{M}^{2+}=\mathrm{Ca}^{2+}$ and $\mathrm{Pb}^{2+}, \mathrm{L}=18$-crown-6 ether (18C6) and dibenzo-18C6 (DB18C6), and $\mathrm{A}^{-}=$picrate ion. The ion-pair formation constant for $\mathrm{M}^{2+}+\mathrm{A}^{-} \rightleftharpoons \mathrm{MA}^{+}$at $\mathrm{M}^{2+}=\mathrm{Pb}^{2+}$ in an aqueous phase was also determined at $298 \mathrm{~K}$ and ionic strength of zero by an extraction of $\mathrm{HA}$ into 1,2-dichloroethane and $\mathrm{Bz}$ with the presence of $\mathrm{Pb}^{2+}$ in the aqueous phase. The $K_{\mathrm{ex}}$ values re-evaluated from the present model were in agreement with those determined by the previous extraction model. Individual distribution constants of $\mathrm{A}^{-}$into $\mathrm{Bz}$ were almost constant irrespective of kinds of $\mathrm{M}^{2+}$ and $\mathrm{L}$ employed. Furthermore, the composition-determination method of the ion pairs, MLA extracted into $\mathrm{Bz}$ was re-examined. Similar analyses were performed in the $\mathrm{SrA}_{2^{-}}, \mathrm{BaA}_{2^{-}} 18 \mathrm{C} 6$, and $\mathrm{SrA}_{2}$-DB18C6 systems without considering the formation of $\mathrm{MA}^{+}$in the aqueous phases.
\end{abstract}

Keywords: extraction constants, individual distribution constant, composition determination, 18-crown-6 ether derivatives, alkaline-earth metal and lead picrates, benzene

\section{Introduction}

Ion-pair complexes $\left(\mathrm{MLA}_{n}\right)$ with crown ethers, L, have dissociated into complex ions, $\mathrm{ML}^{n+}$ or MLA $\mathrm{ML}^{+}$, and pairing anions, $\mathrm{A}^{-}$, at $n=1$ or 2 in organic and aqueous phases (Frensdorff, 1971; Jawaid \& Ingman, 1978; Kolthoff \& Chantooni, 1993; Takeda, 2002; Kikuchi \& Sakamoto, 2000; Kudo, 2013). For example, KLPic dissociates into $\mathrm{KL}^{+}$and picrate ion $\left(\mathrm{Pic}^{-}\right.$) in dichloromethane (Frensdorff, 1971) and water (Takeda, 2002) at L = dibenzo-18-crown-6 ether (DB18C6) and $n=1$ and in 1,2-dichloroethane (DCE) at L = 18-crown-6 ether, 18C6, and $n=1$ (Kolthoff \& Chantooni, 1993); $\mathrm{CaLA}_{2}$ dissociates into $\mathrm{CaLA}^{+}$and $\mathrm{A}^{-}$at $\mathrm{L}=$ dicyclohexyl-18C6, $\mathrm{A}^{-}=$ dipicrylaminate ion, and $n=2$ (Jawaid \& Ingman, 1978). In solvent extraction, the presence of such equilibria means at least the presence (Kudo, Harashima, Katsuta, \& Takeda, 2011; Kudo, Katsuta, \& Takeda, 2012; Kudo, Horiuchi, Katsuta, \& Takeda, 2013) of the individual distribution of $\mathrm{A}^{-}\left(\right.$or $\mathrm{MLA}^{+}$) into the organic phase under the condition that the free $\mathrm{A}^{-}$(or $\mathrm{MLA}^{+}$) is detected in the aqueous phase. Furthermore, this distribution is related to an ion transfer of $\mathrm{A}^{-}$across a liquid/liquid interface, such as nitrobenzene/aqueous and DCE/aqueous ones, and then its distribution data have been connect with electrochemical properties of $\mathrm{A}^{-}$at the interface (Osakai \& Ebina, 1998; Kudo \& Takeuchi, 2013). Accumulation of such data facilitates applications of electrochemical procedures to the field of extraction chemistry with less-polar diluents which were saturated with water.

The authors have studied solvent extraction of divalent metal salts $\mathrm{MA}_{2}$ by L into benzene (Bz) or chloroform and thereby clarified their extraction behavior from an equilibrium-point of view (Takeda \& Kato, 1979; Takeda, 1979; Takeda \& Nishida, 1989; Katsuta, Tsuchiya, \& Takeda, 2000; Kudo et al., 2012). They have also reported an equilibrium analysis for the extraction of $\mathrm{NaMnO}_{4}$ by $18 \mathrm{C} 6$ and 15-crown-5 ether derivatives into DCE and nitrobenzene and then determined individual distribution constants of $\mathrm{MnO}_{4}{ }^{-}$and those of the complex ions, $\mathrm{NaL}^{+}$, 
into DCE and nitrobenzene saturated with water (Kudo et al., 2011). Additionally, the extraction of $\mathrm{CdBr}_{2}$ or $\mathrm{CdPic}_{2}$ by $18 \mathrm{C} 6$ into various diluents with lower polarities, such as Bz, chloroform, dichloromethane, and DCE, has been studied (Kudo et al., 2013). However, these papers (Kudo, Harashima et al., 2011; Kudo, Horiuchi et al., 2013) did not verify what kind of effect changes of $\mathrm{M}^{2+}$ and $\mathrm{L}$ give on magnitudes of the individual distribution constants $\left(K_{\mathrm{D}, \mathrm{A}}\right)$ of $\mathrm{A}^{-}$.

In the present paper, we re-analyzed the $\mathrm{MPic}_{2}-\mathrm{L}$ extraction data into $\mathrm{Bz}$ for $\mathrm{M}=\mathrm{Ca}, \mathrm{Sr}, \mathrm{Ba}$, and $\mathrm{Pb}$ and $\mathrm{L}=18 \mathrm{C} 6$ and DB18C6 by adding the above two equilibria, namely ion-pair formation of $\mathrm{MLPic}^{+}$with $\mathrm{Pic}^{-}$in the organic phase and the distribution of $\mathrm{Pic}^{-}$between the two phases, and an ion-pair formation for $\mathrm{CaPic}^{+}$or $\mathrm{PbPic}^{+}$in the aqueous phase to the previously-proposed model (Takeda \& Kato, 1979) (see the section 3.2). However, the accuracies of the equilibrium analyses were obviously less than those of the analyses reported previously for the $\mathrm{Cd}$ (II) systems (Kudo et al., 2013). In the course of such analyses, the authors discussed a determination-method of the ion-pair formation constant $\left(K_{\mathrm{MA}}\right)$ between divalent metal ions, $\mathrm{M}^{2+}$, and $\mathrm{A}^{-}$in aqueous solutions saturated with DCE or Bz based on an extraction procedure, instead of potentiometric one (Kudo, 2013), and then determined the $K_{\mathrm{PbPic}}$ value at $298 \mathrm{~K}$. Also, the composition-determination (Kudo et al., 2013; Takeda \& Kato, 1979; Takeda, 1979; Takeda \& Nishida, 1989; Katsuta et al., 2000) of species with M(II) extracted into Bz was precisely re-examined, because its procedure has been based on some limitations, such as the presences of an excess of $\mathrm{M}^{2+}$ in the aqueous phase and an excess of $\mathrm{MLA}_{2}$ in the organic one. Moreover, properties of the above extraction systems were briefly re-discussed on the basis of three kinds of extraction constants $\left(K_{\text {ex }}, K_{\text {ex }}\right.$, and $\left.K_{\text {ex }}\right)$ (Kudo et al., 2013), in which the latter two constants were newly determined for the present systems.

This study was mainly carried out for clarifying effects of introduction of these component equilibria on overall extraction equilibrium. Speaking more clearly, (i) does the introduction of their constants to the extraction model (Takeda \& Kato,1979) proposed before largely change the magnitude of the extraction constant, $K_{\text {ex }}$ ? Also, (ii) we would like to clarify whether the introduced $K_{\mathrm{D}, \text { Pic }}$ value becomes a constant or not for an employed diluent. Moreover, (iii) does the limitations described above really hold for the composition-determination in the extraction model presented here? These questions were examined using the above $\mathrm{MPic}_{2}$ and $\mathrm{L}$. At least, the authors have not encountered a detailed discussion on the question (iii). Benzene was selected as a representative among less-polar diluents and expected to be a standard diluent against other ones which will be treated in future.

\section{Method}

\subsection{Chemicals}

Picric acid (HPic; hydrate, 99.5\%) was purchased from Wako Pure Chemical Industries, Japan. Its purity was checked by acid-base titration. Aqueous solutions of lead nitrate \{guaranteed reagent (GR) grade: 99.5\%, Kanto Chemical Co. Ltd., Japan $\}$ were titrated by di-sodium salt of EDTA. Nitric acid was GR grade (60 to $61 \%$, Kanto Chemical Co. Ltd.) and used without any purification. Both diluents, DCE (99.5\%, Kanto Chemical Co. Ltd.) and $\mathrm{Bz}(>99.5 \%$, Wako Pure Chemical Industries), were GR grades; these were washed three-times with water and then saturated with water (Kudo et al., 2013). Other chemicals were of GR grade. A tap water was distilled once and then was purified by passing through Autopure system (Yamato/Millipore, type WT101 UV) (Kudo \& Takeuchi, 2013). This water was employed for preparation of all aqueous solutions.

\subsection{HPic Extraction into DCE in the Presence of $\mathrm{Pb}\left(\mathrm{NO}_{3}\right)_{2}$ in the Aqueous Phase}

First, mixtures composed of $(0.3$ to 1.3$) \times 10^{-3} \mathrm{~mol} \mathrm{~L}^{-1}$ solution of HPic, $(0.1$ to 1.1$) \times 10^{-2} \mathrm{~mol} \mathrm{~L}^{-1}$ one of $\mathrm{HNO}_{3}$, and $(0.1$ to 5.5$) \times 10^{-3} \mathrm{~mol} \mathrm{~L}^{-1}$ one of $\mathrm{Pb}\left(\mathrm{NO}_{3}\right)_{2}$ were prepared in stoppered-glass tubes of about $30 \mathrm{~mL}$, next an equivalent volume of DCE was added to each of these mixtures, and then shaken by hand during 1 minute. These glass tubes thus-obtained were agitated for $2 \mathrm{~h}$ by an Iwaki shaker system (a driving unit: SHK driver; a thermo regulator: type CTR-100) equipped with water-bath (type WTB-24, Iwaki) kept at $298 \mathrm{~K}$. After the mixtures reached equilibrium in the tubes, they were centrifuged for 7 minutes by using a Kokusan centrifuge (type 7163-4.8.20), in order to separate them into the two phases. Then, the $\mathrm{pH}$ values in the resulting aqueous phases were measured using a Horiba pH/ion meter (type F-23) with a Horiba electrode (LAQUA, type 9615). Also, portions of the DCE phases were separated by pipettes, set in other glass-tubes, aqueous solutions of $1 \mathrm{~mol} \mathrm{~L}^{-1}$ $\mathrm{NaOH}$ were added to them, and then HPic extracted into the DCE phases were back-extracted into the aqueous phases with $\mathrm{NaOH}$. Total amounts of $\mathrm{Pic}^{-}$in these aqueous phases were determined at the Pic ${ }^{-}$absorption of 335.0 $\mathrm{nm}$ spectrophotometrically using a Hitachi U-2001 spectrophotometer and then symbolized as [HPic] $]_{\text {DCE }}$. Furthermore, blank experiments were performed for the extraction of HPic into DCE without $\mathrm{Pb}^{2+}$, in order to determine $D_{\mathrm{Pic}}$ values (see Equation 3 for a meaning of this symbol).

An experimental distribution ratio $\left({ }^{\mathrm{Pb}} D_{\mathrm{Pic}}\right)$ for $\mathrm{Pic}^{-}$in the presence of $\mathrm{Pb}\left(\mathrm{NO}_{3}\right)_{2}$ in the aqueous phase were calculated from ${ }^{\mathrm{Pb}} D_{\mathrm{Pic}}={ }^{\mathrm{Pb}}[\mathrm{HPic}]_{\mathrm{DCE}} /\left([\mathrm{HPic}]_{\mathrm{t}}-{ }^{\mathrm{Pb}}[\mathrm{HPic}]_{\mathrm{DCE}}\right)$. Here, $[\mathrm{HPic}]_{\mathrm{t}}$ denotes a total concentration of HPic, 
of which the concentrations were in the range of $(0.3$ to 1.3$) \times 10^{-3} \mathrm{~mol} \mathrm{~L}^{-1}$ (see above). Also, ${ }^{\mathrm{Pb}}[\mathrm{HPic}]_{\mathrm{DCE}}$ shows a molar concentration of HPic in the DCE phase and then the superscript " $\mathrm{Pb}$ " means experimental data for the HPic extraction under the presence of $\mathrm{Pb}^{2+}$ in the aqueous phase (see the section 3.1).

Similarly, the ${ }^{\mathrm{Pb}} D_{\text {Pic }}$ and $D_{\text {Pic }}$ values were determined for the HPic extraction into Bz with and without $\mathrm{Pb}\left(\mathrm{NO}_{3}\right)_{2}$, respectively.

A commercial $\mathrm{Pb}^{2+}$-selective electrode with a solid membrane was employed for the determination of $\mathrm{Pb}^{2+}$ in aqueous solutions of $\mathrm{PbPic}_{2}$. However, its electrode did not clearly respond $\mathrm{Pb}^{2+}$, as similar to the case (Kudo, 2013) of a $\mathrm{Cd}^{2+}$-selective electrode described before. That is, the electrode slightly responded $\mathrm{Pic}^{-}$in the solutions.

\subsection{Re-calculation of the Extraction and Other Constants for the MPic ${ }_{2}-L$ Extraction Systems}

The $K_{\mathrm{ex}}, K_{\mathrm{ex} \pm}, K_{\mathrm{ex}+}$, and $K_{\mathrm{D}, \text { Pic }}$ values were calculated using the same original data as those obtained before by Takeda \& Kato (1979) : see the section 3.2 about details of these symbols. That is, extraction experiments with $\mathrm{M}\left(\mathrm{NO}_{3}\right)_{2}, \mathrm{HPic}$, and 18C6 or DB18C6 were not performed anew. Other procedures for calculation were similar to those (Kudo, Harashima et al., 2011; Kudo, Horiuchi et al., 2013; Kudo, Kobayashi, Katsuta, \& Takeda, 2009) described before.

\section{Theory}

\subsection{Determination of $K_{M A}$ for $M^{2+}$ in the Aqueous Phase by Extraction Experiments}

In order to determine the first-step ion-pair formation constant $\left(K_{\mathrm{MA}}\right)$ in the case of an abnormal respose of the $\mathrm{Pb}^{2+}$ electrode or lack (Kudo et al., 2013) of commercial ISE, such as $\mathrm{Sr}^{2+}$ - and $\mathrm{Ba}^{2+}$-selective electrodes, we first considered the following equilibria.

$$
\begin{aligned}
\mathrm{H}^{+}+\mathrm{A}^{-} & \rightleftharpoons \mathrm{HA} \\
\mathrm{HA} & \rightleftharpoons \mathrm{HA}_{\mathrm{o}}
\end{aligned}
$$

To this HA extraction system, the distribution ratio $\left(D_{\mathrm{A}}\right)$ of $\mathrm{A}^{-}$is expressed as

$$
D_{\mathrm{A}}=[\mathrm{HA}]_{\mathrm{o}} /\left(\left[\mathrm{A}^{-}\right]+[\mathrm{HA}]\right),
$$

where the subscript "o" of $\mathrm{HA}_{\mathrm{o}}$ or $[\mathrm{HA}]_{\mathrm{o}}$ and lack of the subscript denote the organic and aqueous phases, respectively, and HA means an organic acid. Next, a divalent metal salt $\left(\mathrm{MX}_{2}\right)$ is added to this system. If $\mathrm{MX}_{2}$ almost dissociates and then $\mathrm{M}^{2+}$ associates with $\mathrm{A}^{-}$:

$$
\mathrm{M}^{2+}+\mathrm{A}^{-}+2 \mathrm{X}^{-} \rightleftharpoons \mathrm{MA}^{+}+2 \mathrm{X}^{-}
$$

then $D_{\mathrm{A}}$ can be changed into

$$
\left.{ }^{\mathrm{M}} D_{\mathrm{A}}={ }^{\mathrm{M}}[\mathrm{HA}]_{\mathrm{o}} /{ }^{\mathrm{M}}\left[\mathrm{A}^{-}\right]_{\mathrm{o}}+{ }^{\mathrm{M}}[\mathrm{HA}]+\left[\mathrm{MA}^{+}\right]\right)
$$

Here, ${ }^{\mathrm{M}}[\quad]\left(\right.$ or $\left.^{\mathrm{M}}[]_{0}\right)$ denotes the molar concentration at equilibrium in the aqueous (or organic) phase for the HA extraction system with $\mathrm{M}^{2+}$. Equation 5 holds under the conditions that the formation of $\mathrm{MA}_{2}$ in the aqueous phase and the distribution of $\mathrm{M}^{2+}$ or $\mathrm{MA}^{+}$into the organic phase are negligible: namely, $\left[\mathrm{MA}^{+}\right] \gg\left[\mathrm{MA}_{2}\right]$ and $[\mathrm{HA}]_{0}>>$ $\left[\mathrm{MA}^{+}\right]_{\mathrm{o}}+2\left[\mathrm{MA}_{2}\right]_{\mathrm{o}}$. Rearranging Equations 3 and 5, the following equations were given.

$$
\left[\mathrm{H}^{+}\right] / D_{\mathrm{A}}=K_{\mathrm{ex}, \mathrm{HA}}{ }^{-1}+\left(\left[\mathrm{H}^{+}\right] / K_{\mathrm{D}, \mathrm{HA}}\right)
$$

with

$$
\begin{gathered}
K_{\mathrm{ex}, \mathrm{HA}}=[\mathrm{HA}]_{\mathrm{o}} /\left[\mathrm{H}^{+}\right]\left[\mathrm{A}^{-}\right]=K_{\mathrm{D}, \mathrm{HA}} K_{\mathrm{HA}} \\
K_{\mathrm{D}, \mathrm{HA}}=[\mathrm{HA}]_{\mathrm{o}} /[\mathrm{HA}]
\end{gathered}
$$

and

$$
K_{\mathrm{HA}}=[\mathrm{HA}] /\left[\mathrm{H}^{+}\right]\left[\mathrm{A}^{-}\right]
$$

and

$$
{ }^{\mathrm{M}}\left[\mathrm{H}^{+}\right] /{ }^{\mathrm{M}} D_{\mathrm{A}}={ }^{\mathrm{M}} K_{\mathrm{ex}, \mathrm{HA}}{ }^{-1}+\left({ }^{\mathrm{M}}\left[\mathrm{H}^{+}\right] /{ }^{\mathrm{M}} K_{\mathrm{D}, \mathrm{HA}}\right)+\left(\left[\mathrm{MA}^{+}\right]^{\mathrm{M}}\left[\mathrm{H}^{+}\right] /{ }^{\mathrm{M}}[\mathrm{HA}]_{\mathrm{o}}\right) .
$$

Then, subtracting Equation 3a from Equation 5a, we can immediately obtain

$$
\left.\left({ }^{\mathrm{M}}\left[\mathrm{H}^{+}\right] /{ }^{\mathrm{M}} D_{\mathrm{A}}\right)-\left(\left[\mathrm{H}^{+}\right] / D_{\mathrm{A}}\right)=\Delta D_{\mathrm{A}}^{-1}=\left({ }^{\mathrm{M}}\left[\mathrm{H}^{+}\right]-\left[\mathrm{H}^{+}\right]\right) / K_{\mathrm{D}, \mathrm{HA}}+\left(\left[\mathrm{MA}^{+}\right]^{\mathrm{M}}\left[\mathrm{H}^{+}\right]\right)\right)^{\mathrm{M}}[\mathrm{HA}]_{\mathrm{o}} .
$$

Here, the conditions of $K_{\mathrm{ex}, \mathrm{HA}} \approx{ }^{\mathrm{M}} K_{\mathrm{ex}, \mathrm{HA}}$ and $K_{\mathrm{D}, \mathrm{HA}} \approx{ }^{\mathrm{M}} K_{\mathrm{D}, \mathrm{HA}}$ were employed. From Equation 6 , we can easily derive

$$
\left[\mathrm{MA}^{+}\right] \approx\left({ }^{\mathrm{M}}[\mathrm{HA}]_{\mathrm{o}} /{ }^{\mathrm{M}}\left[\mathrm{H}^{+}\right]\right)\left\{\Delta D_{\mathrm{A}}{ }^{-1}-\left({ }^{\mathrm{M}}\left[\mathrm{H}^{+}\right]-\left[\mathrm{H}^{+}\right]\right) / K_{\mathrm{D}, \mathrm{HA}}\right\} .
$$

Since we can determine ${ }^{\mathrm{M}}[\mathrm{HA}]_{\mathrm{o}},{ }^{\mathrm{M}}\left[\mathrm{H}^{+}\right],\left[\mathrm{H}^{+}\right]$, and $\Delta D_{\mathrm{A}}{ }^{-1}$ by extraction experiments and $\mathrm{pH}$ measurements, $\left[\mathrm{MA}^{+}\right]$ is immediately evaluated from Equation 7 ; in computation, the $K_{\mathrm{D}, \mathrm{HA}}$ and $K_{\mathrm{HA}}$ values (see below) for a given ionic 
strength $(I)$ in the aqueous phase were determined by a successive approximation. Mass-balance equations are expressed as a total concentration of species with $\mathrm{A}^{-}$:

$$
[\mathrm{A}]_{\mathrm{t}}={ }^{\mathrm{M}}\left[\mathrm{A}^{-}\right]+{ }^{\mathrm{M}}[\mathrm{HA}]+{ }^{\mathrm{M}}[\mathrm{HA}]_{\mathrm{o}}+\left[\mathrm{MA}^{+}\right]
$$

and as that of species with $\mathrm{M}^{2+}$ :

$$
[\mathrm{M}]_{\mathrm{t}}=\left[\mathrm{M}^{2+}\right]+\left[\mathrm{MA}^{+}\right] .
$$

Therefore, we obtain from Equations 8, 9, and 3d

$$
{ }^{\mathrm{M}}\left[\mathrm{A}^{-}\right]=\left([\mathrm{A}]_{\mathrm{t}}-{ }^{\mathrm{M}}[\mathrm{HA}]_{\mathrm{o}}-\left[\mathrm{MA}^{+}\right]\right) /\left(1+K_{\mathrm{HA}}{ }^{\mathrm{M}}\left[\mathrm{H}^{+}\right]\right)
$$

and

$$
\left[\mathrm{M}^{2+}\right]=[\mathrm{M}]_{\mathrm{t}}-\left[\mathrm{MA}^{+}\right]
$$

Here, we employed $1.95 \mathrm{~mol}^{-1} \mathrm{~L}$ (Kortüm, Vogel, \& Andrussow, 1961) at $298 \mathrm{~K}$ and ionic strength $\left({ }^{\mathrm{M}} I\right.$ or $\left.I\right)$ of 0.1 in water as $K_{\mathrm{HPic}}$. Hence, Equations 7, 9a, and 10 yield $K_{\mathrm{MA}}$ for a given $I$ in the aqueous phase.

$$
{ }^{\mathrm{M}} I=(1 / 2)\left({ }^{\mathrm{M}}\left[\mathrm{H}^{+}\right]+{ }^{\mathrm{M}}\left[\mathrm{A}^{-}\right]+\left[\mathrm{X}^{-}\right]+\left[\mathrm{MA}^{+}\right]+4\left[\mathrm{M}^{2+}\right]\right)
$$

for Equations 1, 2, and 4

$$
={ }^{\mathrm{M}}\left[\mathrm{A}^{-}\right]+2[\mathrm{M}]_{\mathrm{t}}+\left[\mathrm{M}^{2+}\right]
$$

with the charge-balance equation of $2\left[\mathrm{M}^{2+}\right]+{ }^{\mathrm{M}}\left[\mathrm{H}^{+}\right]+\left[\mathrm{MA}^{+}\right]={ }^{\mathrm{M}}\left[\mathrm{A}^{-}\right]+\left[\mathrm{X}^{-}\right]\left(={ }^{\mathrm{M}}\left[\mathrm{A}^{-}\right]+2[\mathrm{M}]_{\mathrm{t}}\right)$ and

$$
I=\left[\mathrm{H}^{+}\right] \approx\left[\mathrm{A}^{-}\right] \text {for Equations } 1 \text { and } 2
$$

Strictly speaking, although a difference between ${ }^{\mathrm{M}} I$ and $I$ is present, the ${ }^{\mathrm{M}} I$ value was used for practical extraction experiments.

\subsection{Analysis of Overall Extraction Equilibria Based on Added Component Equilibria}

To component equilibria expressing an overall extraction equilibrium described by Takeda et al. (Takeda \& Kato, 1979; Takeda \& Nishida, 1989): $\mathrm{L} \rightleftharpoons \mathrm{L}_{\mathrm{o}}, \mathrm{M}^{2+}+\mathrm{L} \rightleftharpoons \mathrm{ML}^{2+}, \mathrm{ML}^{2+}+2 \mathrm{~A}^{-} \rightleftharpoons \mathrm{MLA}_{2,0}, \mathrm{H}^{+}+$ $\mathrm{A}^{-} \rightleftharpoons \mathrm{HA}_{0}$, and Equation 1, the following three component equilibria were added.

$$
\begin{aligned}
\mathrm{M}^{2+}+\mathrm{A}^{-} & \rightleftharpoons \mathrm{MA}^{+} \\
\mathrm{MLA}_{\mathrm{o}}^{+}+\mathrm{A}_{\mathrm{o}}^{-} & \rightleftharpoons \mathrm{MLA}_{2, \mathrm{o}} \\
\mathrm{A}^{-} & \rightleftharpoons \mathrm{A}_{\mathrm{o}}^{-}
\end{aligned}
$$

Therefore, extraction constants, $K_{\mathrm{ex}}$ and $K_{\mathrm{ex} \pm}$, can be defined as follows (Frensdorff, 1971; Jawaid \& Ingman, 1978; Takeda \& Kato, 1979; Kikuchi \& Sakamoto, 2000; Kudo et al., 2013).

$$
\begin{gathered}
K_{\mathrm{ex}}=\left[\mathrm{MLA}_{2}\right]_{\mathrm{o}} /\left(\left[\mathrm{M}^{2+}\right][\mathrm{L}]_{\mathrm{o}}\left[\mathrm{A}^{-}\right]^{2}\right) \\
K_{\text {ex }}=\left[\mathrm{MLA}^{+}\right]_{\mathrm{o}}\left[\mathrm{A}^{-}\right]_{\mathrm{o}} /\left(\left[\mathrm{M}^{2+}\right][\mathrm{L}]_{\mathrm{o}}\left[\mathrm{A}^{-}\right]^{2}\right)
\end{gathered}
$$

Using component equilibrium constants and an ion-pair extraction one $\left(K_{\mathrm{ex}, \mathrm{p}}\right)$, these constants are expressed as $K_{\mathrm{ex}}$ $=K_{\mathrm{ML}} K_{\mathrm{ex}, \mathrm{ip}} / K_{\mathrm{D}, \mathrm{L}}$ (Takeda \& Kato, 1979) and $K_{\mathrm{ex} \pm}=K_{\mathrm{ML}} K_{\mathrm{ex}, \mathrm{ip}} / K_{\mathrm{D}, \mathrm{L}} K_{2}^{\text {org }}$ (Kudo et al., 2013), where these component-equilibrium constants are

$$
\begin{gathered}
K_{\mathrm{ML}}=\left[\mathrm{ML}^{2+}\right] /\left[\mathrm{M}^{2+}\right][\mathrm{L}] \\
K_{\mathrm{D}, \mathrm{L}}=[\mathrm{L}]_{\mathrm{o}} /[\mathrm{L}] \\
K_{2}^{\mathrm{org}}=\left[\mathrm{MLA}_{2}\right]_{\mathrm{o}} /\left[\mathrm{MLA}^{+}\right]_{\mathrm{o}}\left[\mathrm{A}^{-}\right]_{\mathrm{o}} .
\end{gathered}
$$

Also, $K_{\text {ex,ip }}$ is defined as $\left[\mathrm{MLA}_{2}\right]_{0} /\left[\mathrm{ML}^{2+}\right]\left[\mathrm{A}^{-}\right]^{2}$ (Takeda \& Kato, 1979) which is usually resolved into $\left[\mathrm{MLA}^{+}\right] /\left[\mathrm{ML}^{2+}\right]\left[\mathrm{A}^{-}\right]\left(=K_{1}\right),\left[\mathrm{MLA}_{2}\right] /\left[\mathrm{MLA}^{+}\right]\left[\mathrm{A}^{-}\right]\left(=K_{2}\right)$, and $\left[\mathrm{MLA}_{2}\right]_{\mathrm{o}} /\left[\mathrm{MLA}_{2}\right]\left(=K_{\mathrm{D}, \mathrm{MLA} 2}\right)$. Unfortunately, these $K_{1}, K_{2}$, and $K_{\mathrm{D}, \mathrm{MLA} 2}$ values have not been reported systematically, except for their values of the $\mathrm{CdBr}_{2}$ and $\mathrm{CdPic}_{2}$ extraction systems with 18C6 or benzo-18C6 (Kudo et al., 2013; Kudo et al., 2009). Hence, we could not use these values as the component equilibrium constants in this study.

We assumed that $\Sigma\left[\mathrm{MLA}_{n}^{(2-n)+}\right]_{0}$ values at $n=1,2$ were obtained experimentally and then defined $K_{\mathrm{ex}}{ }^{\text {mix }}$ as $\Sigma\left[\mathrm{MLA}_{n}{ }^{(2-n)^{+}}\right]_{\mathrm{o}} /\left(\left[\mathrm{M}^{2+}\right][\mathrm{L}]_{\mathrm{o}}\left[\mathrm{A}^{-}\right]^{2}\right)$ (Kudo et al., 2013) and the value at $n=0$ was neglected because of low


been determined by AAS (Takeda \& Kato, 1979; Takeda, 1979; Kudo et al., 2013). From this definition, we can easily derive the following equations. 


$$
\begin{aligned}
\log K_{\mathrm{ex}}{ }^{\operatorname{mix}} & =\log \left\{K_{\mathrm{ex}}+K_{\mathrm{D}, \mathrm{A}} /\left(\left[\mathrm{M}^{2+}\right][\mathrm{L}]_{\mathrm{o}}\left[\mathrm{A}^{-}\right]\right)\right\} \\
& =\log \left\{K_{\mathrm{ex}}+\left(K_{\mathrm{ex} \pm} /\left[\mathrm{M}^{2+}\right][\mathrm{L}]_{\mathrm{o}}\right)^{1 / 2} /\left[\mathrm{A}^{-}\right]\right\}
\end{aligned}
$$

So, one can obtain immediately the $K_{\mathrm{ex}}$ and $K_{\mathrm{D}, \mathrm{A}}$ or $K_{\text {ex } \pm}$ values from plots of $\log K_{\mathrm{ex}}{ }^{\text {mix }}$ versus $-\log \left(\left[\mathrm{M}^{2+}\right][\mathrm{L}]_{\mathrm{o}}\left[\mathrm{A}^{-}\right]\right)$ or $-\log \left\{\left[\mathrm{A}^{-}\right]\left(\left[\mathrm{M}^{2+}\right][\mathrm{L}]_{\mathrm{o}}\right)^{1 / 2}\right\}$ (Kudo et al., 2013), respectively, in a given range of $I$ in the aqueous phase by using a non-linear regression analysis to these plots. Here, $\left[\mathrm{M}^{2+}\right],[\mathrm{L}]_{\mathrm{o}}$, and $\left[\mathrm{A}^{-}\right]$have been expressed as the functions of $f\left([\mathrm{~L}]_{0},\left[\mathrm{~A}^{-}\right]\right.$, some $\left.K\right), g\left(\left[\mathrm{M}^{2+}\right],\left[\mathrm{A}^{-}\right]\right.$, some $\left.K\right)$, and $h\left(\left[\mathrm{M}^{2+}\right],[\mathrm{L}]_{0}\right.$, some $\left.K\right)$, respectively, and then determined by the successive approximation (Kudo, Horiuchi et al., 2013; Kudo, Kobayashi et al., 2009).

By Equation 16, the relation $\left[\mathrm{MLA}^{+}\right]_{\mathrm{o}}=\left[\mathrm{A}^{-}\right]_{\mathrm{o}}=\left[\mathrm{A}^{-}\right]\left(K_{\mathrm{ex} \pm}\left[\mathrm{M}^{2+}\right][\mathrm{L}]_{\mathrm{o}}\right)^{1 / 2}$ is given, where $\left[\mathrm{MLA}^{+}\right]_{\mathrm{o}}=\left[\mathrm{A}^{-}\right]_{\mathrm{o}}$ is a charge-balance equation in the organic phase. Using this relation and the experimental data of $\Sigma\left[\mathrm{MLA}_{n}{ }^{(2-n)+}\right]_{0}$ and $K_{\text {ext }}$, we will evaluate a mole fraction, $\left[\mathrm{MLA}^{+}\right]_{0} / \Sigma\left[\mathrm{MLA}_{n}^{(2-n)+}\right]_{\mathrm{o}}$, as described below.

\section{Results and Discussion}

\subsection{Determination of Ion-Pair Formation Constants of PbPic ${ }^{+}$in the Aqueous Phase}

Figure 1 shows a plot of $\log K_{\mathrm{PbPic}}$ versus $\left({ }^{\mathrm{M}} I\right)^{1 / 2}$ for the extraction of HPic into DCE in the presence of $\mathrm{Pb}\left(\mathrm{NO}_{3}\right)_{2}$ in the aqueous phase. These experimental ionic strength values, ${ }^{\mathrm{Pb}} \mathrm{I} / \mathrm{mol} \mathrm{L} \mathrm{L}^{-1}$, of ionic species in the aqueous phases were in the range of 0.003 to 0.017 . A broken line is a line with a correlation coefficient $(R)=0.751$ due to a non-linear regression analysis to the equation, $\log K_{\mathrm{MA}}=\log K_{\mathrm{MA}}{ }^{0}-4 \times 0.511\left\{\left({ }^{\mathrm{M}} I\right)^{1 / 2} /\left[1+\left({ }^{\mathrm{M}} I\right)^{1 / 2}\right]-0.3^{\mathrm{M}} I\right\}$ (Kudo, 2013), where $K_{\mathrm{MA}}{ }^{0}$ refers to $K_{\mathrm{MA}}$ at ${ }^{\mathrm{M}} I \rightarrow 0$ and we assumed that the activity coefficient of PbPic ${ }^{+}$in water equals that of Pic ${ }^{-}$. The curve fitting of the plot in Figure 1 to the other equation like $\log K_{\mathrm{MA}}=\log K_{\mathrm{MA}}{ }^{0}-$ $4 \times 0.511\left\{\left({ }^{\mathrm{M}} I\right)^{1 / 2} /\left[1+\left({ }^{\mathrm{M}} I\right)^{1 / 2}\right]-C^{\mathrm{M}} I\right\}$ was possible $(C \approx-6$ at $R=0.961)$, but it is difficult to explain the numerical value of its parameter, $C$. Therefore, the authors gave up the curve fittings to other equations, although the $R$ values of the fittings to the Davies and extended Debye-Hückel equations were smaller than that to the other. Their smaller $R$ values may mean that the above assumption of activity coefficients between $\mathrm{PbPic}^{+}$and $\mathrm{Pic}^{-}$is not effective.

The regression analysis yielded $\log K_{\mathrm{PbPic}}{ }^{0}=2.00 \pm 0.02$ in water saturated with DCE (see Figure 1); $2.00 \pm 0.02$ from the extended Debye-Hückel equation (Kudo, 2013) with an ion size parameter of $4.5 \AA$ for $\mathrm{Pb}^{2+}$ (Kielland, 1937). Similarly, the analysis for the HPic extraction into Bz gave $\log K_{\mathrm{PbPic}}{ }^{0}=1.97 \pm 0.07$ in water saturated with $\mathrm{Bz}$ at $R=0.462$ and a number $(N)$ of run $=5 ; 1.96 \pm 0.07$ was obtained from the Debye-Hückel equation. In spite of a difference between the diluents, both the $\log K_{\mathrm{PbPic}}{ }^{0}$ values agreed with each other within experimental errors. The experiments for confirming the $K_{\mathrm{MPic}}$ values at $\mathrm{M}=\mathrm{Ca}$ and $\mathrm{Cd}$ are in progress, in order to establish the present $K_{\mathrm{MA}}$-determination method; we are now obtaining the finding that its value (= about $100 \mathrm{~mol}^{-1} \mathrm{~L}$ ) for $\mathrm{CdPic}^{+}$ determined by this method is in accord with that $(=108,107)$ (Kudo, 2013) done by potentiometry with ISE. Strictly speaking, these values may not be the thermodynamic equilibrium constant but it has no problem that we ordinarily use their values for an equilibrium analysis in solvent extraction.

\subsection{For the Experimental Determination of Composition of Species Extracted into Benzene}

For the present extraction systems, compositions of their extracted species have been determined by the plot of log $\left(D_{\mathrm{M}}{ }^{\text {expl. }} /\left[\mathrm{Pic}^{-}\right]^{2}\right)$ versus $\log [\mathrm{L}]_{0}$ and that of $\log \left(D_{\mathrm{M}}{ }^{\text {expl. }} /[\mathrm{L}]_{0}\right)$ versus $\log \left[\mathrm{Pic}^{-}\right]$(Takeda \& Kato, 1979; Takeda, 1979; Takeda \& Nishida, 1989). Here, $D_{\mathrm{M}}{ }^{\text {expl. }}$ is a distribution ratio of species with $\mathrm{M}(\mathrm{II})$, obtained from experiments:

$$
\begin{gathered}
D_{\mathrm{M}}^{\text {expl. }}=\left(\left[\mathrm{MLPic}_{2}\right]_{\mathrm{o}}+\left[\mathrm{MLPic}^{+}\right]_{\mathrm{o}}+\left[\mathrm{ML}_{2} \mathrm{Pic}_{2}\right]_{\mathrm{o}}+\cdots\right) /\left(\left[\mathrm{M}^{2+}\right]+\left[\mathrm{ML}^{2+}\right]+\left[\mathrm{MPic}^{+}\right]+\cdots\right) \\
f\left[\mathrm{MLPic}_{2}\right]_{\mathrm{o}} /\left[\mathrm{M}^{2+}\right]=f D_{\mathrm{M}}
\end{gathered}
$$

and $D_{\mathrm{M}}$ is defined as $\left[\mathrm{MLPic}_{2}\right]_{\mathrm{o}} /\left[\mathrm{M}^{2+}\right] . D_{\mathrm{M}}{ }^{\text {expl. }}$ is equal to $D_{\mathrm{M}}$ under the condition of $f=1$ (Kudo, Harashima et al., 2011; Kudo, Horiuchi et al., 2013) or those of $\left[\mathrm{MLPic}_{2}\right]_{\mathrm{o}}>>\left[\mathrm{MLPic}^{+}\right]_{\mathrm{o}}+\left[\mathrm{ML}^{2+}\right]_{\mathrm{o}}+\left[\mathrm{ML}_{2} \mathrm{Pic}_{2}\right]_{\mathrm{o}}+\cdots$ and $\left[\mathrm{M}^{2+}\right] \gg>$ $\left[\mathrm{ML}^{2+}\right]+\left[\mathrm{MPic}^{+}\right]+\cdots($ Takeda \& Kato, 1979; Takeda, 1979; Takeda \& Nishida, 1989). The experimental values of slopes for the plots were 0.93 to the former plot and 2.4 to the latter one for the $\mathrm{CaPic}_{2}-18 \mathrm{C} 6$ system, 1.0 and 2.25

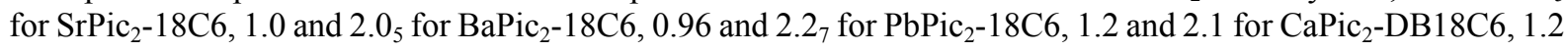
and $2.0_{8}$ for $\mathrm{SrPic}_{2}$-DB18C6, and 1.0 and 1.8 for $\mathrm{PbPic}_{2}$-DB18C6. As an example, the plot for the $\mathrm{PbPic}_{2}$-DB18C6 system is shown in Figure 2. The upper plot showed the slope of about unity against $\log [\mathrm{L}]_{\mathrm{Bz}}$, while the lower one does that of about two against $\log \left[\mathrm{Pic}^{-}\right]$, indicating the extraction of $\mathrm{Pb}(\mathrm{DB} 18 \mathrm{C} 6) \mathrm{Pic}_{2}$ into $\mathrm{Bz}$. Similar tendencies were observed for the plots of the other systems. These results indicate that the extracted major-species are $\mathrm{MLPic}_{2}$, as reported before (Takeda \& Kato, 1979; Takeda, 1979; Takeda \& Nishida, 1989; Kudo et al., 2013).

The experimental mean-values of $f$ with a standard deviation were calculated to be $0.98 \pm 0.03$ for the $\mathrm{CaPic}_{2}-18 \mathrm{C} 6$ 
extraction system, $0.99 \pm 0.04$ for $\mathrm{SrPic}_{2}-18 \mathrm{C} 6,0.51 \pm 0.04$ \{estimated from the data in Kudo et al. (2013)\} for $\mathrm{CdPic}_{2}-18 \mathrm{C} 6,1.8 \pm 0.6$ for $\mathrm{PbPic}_{2}-18 \mathrm{C} 6,1.3 \pm 0.1$ for $\mathrm{CaPic}_{2}$-DB18C6, $1.1 \pm 0.1$ for $\mathrm{SrPic}_{2}$-DB18C6, and $0.95 \pm$ 0.01 for $\mathrm{PbPic}_{2}$-DB18C6. Although deviations of the $f$ values from unity for the $\mathrm{Cd}(\mathrm{II})-, \mathrm{Pb}(\mathrm{II})-18 \mathrm{C} 6$, and $\mathrm{Ca}(\mathrm{II})$-DB18C6 systems are larger than the others, the above results demonstrate validity of the above condition, $f$ $=\left\{1+\left(\left[\mathrm{MLPic}^{+}\right]_{\mathrm{o}}+\cdots\right) /\left[\mathrm{MLPic}_{2}\right]_{\mathrm{o}}\right\} /\left\{1+\left(\left[\mathrm{ML}^{2+}\right]+\left[\mathrm{MPic}^{+}\right]+\cdots\right) /\left[\mathrm{M}^{2+}\right]\right\} \approx 1$, in the present data analysis and consequently effectiveness of such plots determining the composition. Therefore, one may suppose that an accuracy on the composition-determination of the extracted species based on the relation (Takeda \& Kato, 1979; Takeda, 1979; Takeda \& Nishida, 1989) of $\log \left(f D_{\mathrm{M}} /\left[\mathrm{A}^{-}\right]^{2}\right)=a \log [\mathrm{L}]_{\mathrm{o}}+\log K_{\mathrm{ex}}^{\text {inter. }}$ for $\mathrm{M}^{2+}$ to $a \mathrm{~L}\left\{\operatorname{or} \log \left(f D_{\mathrm{M}} /[\mathrm{L}]_{\mathrm{o}}\right)\right.$ $=b \log \left[\mathrm{A}^{-}\right]+\log K_{\mathrm{ex}}^{\text {inter. }}$ for $\mathrm{M}^{2+}$ to $\left.b \mathrm{~A}^{-}\right\}$primarily depends on the magnitude of the $f$ value, namely a degree of the deviation of $a$ (or $b$ ) from 1 (or 2). Here, $\log K_{\mathrm{ex}}^{\text {inter. }}$ denotes the intercept of the plot and the relation of $\log K_{\mathrm{ex}}$ inter. $=\log f K_{\text {ex }}$ holds (Kudo et al., 2013).

However, a comparison of the $a$ values with the $f$ ones suggests that when $f$ is in the range of 0.5 to 1.8 at least, the $a$ values do not largely deviate from 1 ; see above for the $a$ value of the $\mathrm{Pb}(\mathrm{II})-18 \mathrm{C} 6$ system and the $a$ value evaluated for the $\mathrm{CdPic}_{2}-18 \mathrm{C} 6$ system was $1.0_{8}$ at $R=0.966$ (Kudo et al., 2013). From rearranging the experimental equation, $\log \left(0.51 D_{\mathrm{Cd}^{d}} /\left[\mathrm{Pic}^{-}\right]^{2}\right)=1.0_{8} \log [18 \mathrm{C} 6]_{\mathrm{Bz}}+\log K_{\mathrm{ex}}$ inter. , into $\log \left(D_{\mathrm{Cd}} /\left[\mathrm{Pic}^{-}\right]^{2}\right) \approx 1.0_{8} \log$ $[18 \mathrm{C} 6]_{\mathrm{Bz}}+\log \left(K_{\mathrm{ex}}^{\text {inter. }} / 0.51\right)$, we can easily see that the $f$ value is less sensitive to the slope $a$ than to the intercept $\log K_{\text {ex }}^{\text {inter. }}$. In other words, an effect of $f$ is directed to $\log K_{\text {ex }}^{\text {inter. }}$ but its effect is limited to the composition $a$. The same is true of rearranging the equation, $\log \left(1.8 D_{\mathrm{Pb}} /\left[\mathrm{Pic}^{-}\right]^{2}\right)=0.96 \log [18 \mathrm{C} 6]_{\mathrm{Bz}}+\log K_{\mathrm{ex}}$ inter. into $\log$ $\left(D_{\mathrm{Pb}} /\left[\mathrm{Pic}^{-}\right]^{2}\right) \approx 0.96 \log [18 \mathrm{C} 6]_{\mathrm{Bz}}+\log \left(K_{\mathrm{ex}}^{\text {inter. }} / 1.8\right)$. Similarly, the equation, $\log \left(1.3 D_{\mathrm{Ca}} /\left[\mathrm{Pic}^{-}\right]^{2}\right)=1.2 \log$ $[\mathrm{DB} 18 \mathrm{C} 6]_{\mathrm{Bz}}+\log K_{\mathrm{ex}}{ }^{\text {inter. }}$ can be rearranged into $\log \left(D_{\mathrm{Ca}} /\left[\mathrm{Pic}^{-}\right]^{2}\right) \approx 1.2 \log [\mathrm{DB} 18 \mathrm{C} 6]_{\mathrm{Bz}}+\log \left(K_{\mathrm{ex}}{ }^{\text {inter. }} / 1.3\right)$. These results are supported by the fact that a plot of a versus $f$ for the above M(II)-L systems, except for the $\mathrm{Ba}(\mathrm{II})-18 \mathrm{C} 6$ one, gave the $R$ value of $|0.089|$.

The plots yield $\log f K_{\text {ex }}$ as the intercepts (Kudo et al., 2013). This fact indicates that the intercepts deviate from the true $\log K_{\mathrm{ex}}$ values by $\log f$. On this ground, obtaining the $\log K_{\mathrm{ex}}$ value from the intercepts of the plots is not preferable in general.

\subsection{Determination of Fundamental Equilibrium Constants}

After the composition-determination of the extracted species, we can determine next the extraction constants by using Equations 20 and 20a. Figures 3 and 4 show the plots of $\log K_{\mathrm{ex}}{ }^{\operatorname{mix}}$ versus $-\log \left(\left[\mathrm{M}^{2+}\right][\mathrm{L}]_{\mathrm{o}}\left[\mathrm{A}^{-}\right]\right)$and $-\log$ $\left\{\left[\mathrm{A}^{-}\right]\left(\left[\mathrm{M}^{2+}\right][\mathrm{L}]_{\mathrm{o}}\right)^{1 / 2}\right\}$ for the $\mathrm{PbPic}_{2}-18 \mathrm{C} 6$ extraction system, respectively. Both the plots yielded curves which rose with increases in the prameters of the x-axises. The regression analyses of these plots gave $\left(K_{\text {ex }} / \mathrm{mol}^{-3} \mathrm{~L}^{3}\right)=(1.9 \pm$ $1.2) \times 10^{11}$ with $K_{\mathrm{D}, \text { Pic }}=\left(2.4_{9} \pm 0.4_{9}\right) \times 10^{-2}$ (Figure 3) and $\left(K_{\mathrm{ex}} / \mathrm{mol}^{-3} \mathrm{~L}^{3}\right)=\left(4.4_{3} \pm 0.9_{1}\right) \times 10^{11}$ with $\left(K_{\mathrm{ex}} / \mathrm{mol}^{-2} \mathrm{~L}^{2}\right)$ $=(2.6 \pm 1.3) \times 10^{6}$ (Figure 4). The same plots for other $\mathrm{MPic}_{2}-\mathrm{L}$ extraction-systems as those for the $\mathrm{PbPic}_{2}-18 \mathrm{C} 6$ one yielded the same kinds of constants.

Table 1 lists logarithmic values of the fundamental equilibrium constants determined in this study, together with the $\log K_{\text {ex }}$ values (Takeda \& Kato, 1979) reported previously. Marked differences between the present $\log K_{\text {ex }}$ values and the previously-reported ones (Takeda \& Kato, 1979) were not observed. The $\log K_{\text {ex }}$ values were in the order $\mathrm{M}=\mathrm{Cd}<<\mathrm{Ca}<\mathrm{Sr} \leq \mathrm{Ba}<\mathrm{Pb}$ for $\mathrm{L}=18 \mathrm{C} 6$ and $\mathrm{Ca}<\mathrm{Sr}<\mathrm{Pb}$ for DB18C6. The same seems to be true of $\log$ $K_{\text {ex } \pm}$ orders. The $\log K_{\text {D,Pic }}$ values were almost a constant within experimental errors, except for the $\mathrm{Cd}(\mathrm{II})$ extraction system. This fact suggests validity of the present procedure, although the experimental $I$ values are different from each other (see Table 1). At the same time, this suggests that there is an individual value for the distribution constant of single $\mathrm{Pic}^{-}$into $\mathrm{Bz}$ (see Figure 5). The large deviation from the log $K_{\mathrm{D} \text {,Pic }}$ value of the $\mathrm{Cd}(\mathrm{II})$ system shows that the other $\log K_{\mathrm{D} \text {,Pic }}$ values are apparent ones which depend on distribution-abilities of $\mathrm{MLPic}^{+}\left(\right.$or ML ${ }^{2+}$ ) into Bz (Kudo et al., 2013). That is, considering an electroneutrality between ionic species in the $\mathrm{Bz}$ phase, $\mathrm{Pic}^{-}$has to distribute into $\mathrm{Bz}$ in the process such as $\mathrm{Pic}^{-}+\mathrm{MLPic}^{+} \rightleftharpoons \mathrm{Pic}_{\mathrm{Bz}}^{-}+\mathrm{MLPic}_{\mathrm{Bz}}^{+}$.

\subsection{For Component Equilibrium and Ion-Pair Extraction Constants}

The component equilibrium constants and $K_{\text {ex,ip }}$ relevant to $K_{\text {ex }}$ and $K_{\text {ext }}$ are summarized in Table 2. As can be seen from this table, the reported $\log K_{\mathrm{ML}}$ values (Takeda \& Kato, 1979; Høiland, Ringseth, \& Brun, 1979; Shchori, Nae, \& Jagur-Grodzinski, 1975) are in the order $\mathrm{M}=\mathrm{Cd}<<\mathrm{Ca}<<\mathrm{Sr}<\mathrm{Ba}<\mathrm{Pb}$ for $\mathrm{L}=18 \mathrm{C} 6$ and $\mathrm{Ca}<\mathrm{Sr}<\mathrm{Pb}$ for DB18C6. The $\log K_{\text {ex,ip }}$ values were also in the order $\mathrm{Cd}<<\mathrm{Ba}<\mathrm{Ca}<\mathrm{Sr}<\mathrm{Pb}$ for 18C6; their values were close to those (Takeda \& Kato, 1979) reported before (see Table 2). Except for the $\mathrm{BaPic}_{2}-18 \mathrm{C} 6$ system, both the orders of $\log K_{\mathrm{M} 18 \mathrm{C} 6}$ and $\log K_{\mathrm{ex}, \mathrm{p}}$ control the $\log K_{\mathrm{ex}}$ one at $\mathrm{L}=18 \mathrm{C} 6$. This result is the same as that reported before (Takeda $\&$ Kato, 1979). Moreover, comparing the present $\log K_{\text {ex,ip }}$ and $\log K_{\mathrm{MDB} 18 \mathrm{C} 6}$ values with the previously-reported ones (Takeda \& Kato, 1979) at DB18C6, their orders reflect the $\log K_{\text {ex }}$ order. The same is true of the $\log K_{\text {ext }}$ orders for both the L. 
The $K_{2}{ }^{\text {org }}$ value at $I_{\mathrm{o}}, I$ in the organic phase, can be easily calculated from the relation of $K_{\text {ex }} / K_{\text {ex }}=K_{2}{ }^{\text {org }}$ (Kudo et al., 2013). Here, the $I_{\mathrm{o}}$ value at $\mathrm{o}=\mathrm{Bz}$ was estimated from the charge balance equation (see Table 2 and the theoretical section 3.2) by assuming $\left[\mathrm{MLA}^{+}\right]_{0} \gg 2\left[\mathrm{ML}^{2+}\right]_{0}+2\left[\mathrm{M}^{2+}\right]_{\mathrm{o}}+\left[\mathrm{H}^{+}\right]_{\mathrm{o}} ; I_{\mathrm{o}}=(1 / 2)\left(\left[\mathrm{MLA}^{+}\right]_{\mathrm{o}}+\left[\mathrm{A}^{-}\right]_{0}\right)=\left[\mathrm{A}^{-}\right]_{\mathrm{o}}$ $\left(=\left[\mathrm{MLA}^{+}\right]_{\mathrm{o}}\right)$. The $\log K_{2}^{\mathrm{Bz}}$ values in Table 2 were in the order $\mathrm{M}=\mathrm{Pb}<\mathrm{Ca} \leq \mathrm{Sr}<\mathrm{Cd}$ for $\mathrm{L}=18 \mathrm{C} 6$ and $\mathrm{Ca} \leq \mathrm{Sr} \leq$ $\mathrm{Pb}$ for $\mathrm{DB} 18 \mathrm{C} 6$. The $R_{\mathrm{IR}}$ values of these metal ions at a coordination number of 6 were $1.00 \AA$ for $\mathrm{Ca}(\mathrm{II}), 0.95$ for $\mathrm{Cd}(\mathrm{II}), 1.19$ for $\mathrm{Pb}(\mathrm{II})$, and 1.18 for $\mathrm{Sr}(\mathrm{II})$, where $R_{\mathrm{IR}}$ refers to an effective ionic radius (Shannon, 1976). In comparison with $R_{\mathrm{IR}}$, a coulombic force around M(II) seems to be ineffective for the order of $\log K_{2}^{\mathrm{Bz}}$. If the constants $K_{2}^{\mathrm{Bz}}$ satisfy a general tendency, $K_{1}>K_{2}$, such as stepwise complex-formation constants, their overall constants, $K_{1}{ }^{\mathrm{Bz}} K_{2}^{\mathrm{Bz}}$, can become very large. This suggests the condition of $\left[\mathrm{MLPic}^{+}\right]_{\mathrm{Bz}}<\left[\mathrm{MLPic}_{2}\right]_{\mathrm{Bz}}$ at least. Except for $\mathrm{Pb}(18 \mathrm{C} 6) \mathrm{Pic}^{+}$, the following results were consistent with this suggestion.

The mole fractions, $\left[\mathrm{MLPic}^{+}\right]_{\mathrm{Bz}} / \Sigma\left[\mathrm{MLPic}_{n}{ }^{(2-n)+}\right]_{\mathrm{Bz}}$, of MLPic ${ }^{+}$against all species with $\mathrm{M}(\mathrm{II})$ in the Bz phases were in the ranges of $0.04-0.11$ for the $\mathrm{Ca}(\mathrm{II})-18 \mathrm{C} 6$ system, $0.03-0.11$ for $\mathrm{Sr}(\mathrm{II})-18 \mathrm{C} 6,0.32-0.53$ for $\mathrm{Pb}(\mathrm{II})-18 \mathrm{C} 6$, 0.26-0.42 for $\mathrm{Ca}(\mathrm{II})-\mathrm{DB} 18 \mathrm{C} 6,0.07-0.23$ for $\mathrm{Sr}(\mathrm{II})-\mathrm{DB} 18 \mathrm{C} 6$, and $0.02-0.05$ for $\mathrm{Pb}(\mathrm{II})-\mathrm{DB} 18 \mathrm{C} 6$. Thus, the larger mole fraction of $\mathrm{Pb}(18 \mathrm{C} 6) \mathrm{Pic}^{+}$and the smallest $\log K_{2}{ }^{\mathrm{Bz}}$ value (see above) should be reflected to the highest log $K_{\mathrm{D}, \mathrm{Pic}}$ value for the $\mathrm{PbPic}_{2}-18 \mathrm{C} 6$ system of the values examined (see Table 1).

Also, tendencies of differences between the $\log K_{\text {ex }}$ values listed in Table 1 were in the order $\mathrm{Ca}\left(-0.2_{4}\right)<\mathrm{Cd}$ $(-0.03) \leq \mathrm{Sr}\left(+0.0_{1}\right)\left\{\leq \mathrm{Ba}\left(+0.0_{1}\right)\right\}<\mathrm{Pb}\left(+0.1_{3}\right)$ for $18 \mathrm{C} 6$ and $\mathrm{Ca}\left(-0.0_{5}\right) \leq \mathrm{Pb}(-0.01) \leq \mathrm{Sr}(+0.06)$ for DB18C6. Comparing this order with that of $\log K_{2}^{\mathrm{Bz}}$, it seems that the larger the $\log K_{2}{ }^{\mathrm{Bz}}$ values are, the smaller the differences between $\log K_{\text {ex }}$ ones become, except for the $\mathrm{CaPic}_{2}-\mathrm{L}$ systems. Now, we can not explain deviations of the $\mathrm{CaPic}_{2}-\mathrm{L}$ systems from the orders.

The $\log K_{\mathrm{MPic}}$ values determined at $I \rightarrow 0$ were in the order $\mathrm{M}^{\mathrm{II}}=\mathrm{Ca}\left(1.9_{4}\right)$ (Kudo, Takeuchi, Kobayashi, Katsuta, $\&$ Takeda, 2007) $\leq \mathrm{Pb} \leq \mathrm{Cd}$ (2.03) (Kudo et al., 2007). The same was true of the $\log K_{\mathrm{MPic}}$ values evaluated at the $I$ values in Table 2. The order is not in accord with that of the coulombic force around $\mathrm{M}(\mathrm{II}): \mathrm{Pb}<\mathrm{Ca}<\mathrm{Cd}$. On the other hand, hydration free energies (Marcus, 1997) $\left(-\Delta G_{\mathrm{h}}{ }^{\circ} / \mathrm{kJ} \mathrm{mol}^{-1}\right)$ are in the order $\mathrm{Pb}^{2+}(1434)<\mathrm{Ca}^{2+}(1515)<$ $\mathrm{Cd}^{2+}$ (1763). These facts suggest incomplete dehydration around these $\mathrm{M}^{2+}$ in water (Kudo et al., 2007; Rudolf \& Irmer, 1994; Kudo, 2013). There was no large difference among the log $K_{\mathrm{HPic}}$ values of the extraction systems employed (see $\log K_{\mathrm{HA}}$ in Table 2). This fact obviously comes from the small $I$ range of 0.0030 to 0.016 in the extraction experiments.

\subsection{For Other Extraction Constant $K_{\text {ex+ }}$}

We can define $K_{\text {ex }}$ as $\left[\mathrm{MLA}^{+}\right]_{\mathrm{o}} /\left(\left[\mathrm{M}^{2+}\right][\mathrm{L}]_{\mathrm{o}}\left[\mathrm{A}^{-}\right]\right)$(Kudo et al., 2013) and relate it to $K_{\text {ext. }}$. According to their thermodynamic cycle, $K_{\text {ex } \pm}$ is expressed as

$$
K_{\text {ext }}=K_{\text {ex }} K_{\mathrm{D}, \mathrm{A}} .
$$

Using this equation, the $\log K_{\text {ex+ }}$ values were estimated from Table 1 to be 3.8 for the $\mathrm{CaPic}_{2^{-}}, 5.9$ for $\mathrm{SrPic}_{2^{-}}$, -1.4 for $\mathrm{CdPic}_{2}-$, and 8.0 for $\mathrm{PbPic}_{2}-18 \mathrm{C} 6$ systems and 1.4 for the $\mathrm{CaPic}_{2}-1.8$ for $\mathrm{SrPic}_{2}-$, and 3.4 for $\mathrm{PbPic}_{2}$-DB18C6 systems. Therefore, if Equation 22 holds for the Bz extraction systems, then a plot of $\log K_{\text {ex }}$ versus $\log K_{\mathrm{ex}}$ will yield a straight line with a slope of unity and an intercept of $\log K_{\mathrm{D}, \mathrm{A}}$. Figure 5 shows such a plot for all the extraction systems analyzed. Except for the points of the $\mathrm{CdPic}_{2}$ - and $\mathrm{PbPic}_{2}-18 \mathrm{C} 6$ systems, the plot gave a straight line with the slope of $0.98_{4}$ and the intercept of -3.20 at $R=0.980$. These values are in good agreement with those described above: for example, the geometric mean-value of the $\log K_{\mathrm{D} \text {,Pic }}$ values was estimated to be $-3.1_{2} \pm 0.7_{3}$ at $N=7$ in Table 1, except for the Cd(II) system. Similarly, a plot for the relation of $\log$ $\left(K_{\text {ex }} / K_{\text {ex }}\right)=\log K_{2}{ }^{\text {org }}+\log K_{\mathrm{D}, \mathrm{A}}$ was examined. However, a correlation between the $\log \left(K_{\text {ex }} / K_{\text {ex }}\right)$ and $\log K_{2}^{\text {org }}$ values was not obtained.

The $\log K_{\text {ex }}$ value (= $3.8 \pm 0.6$ ) for $\mathrm{CaPic}_{2}-18 \mathrm{C} 6$ extraction system is comparable to the $\log K_{\text {ex }}{ }^{\prime}$ one $(=3.503)$ (Kudo, Usami, Katsuta, \& Takeda, 2006) for NaPic-18C6 one: $K_{\mathrm{ex}}{ }^{\prime}=[\mathrm{NaLPic}]_{\mathrm{Bz}} /\left(\left[\mathrm{Na}^{+}\right][\mathrm{L}]_{\mathrm{Bz}}\left[\mathrm{Pic}^{-}\right]\right)$at $\mathrm{L}=18 \mathrm{C} 6$. However, the $\log K_{\text {ex,ip }+}(\mathrm{Ca})$ value is somewhat larger than the $\log K_{\text {ex,ip }}{ }^{\prime}(\mathrm{Na})$ one: $\log K_{\text {ex,ip }}{ }^{\prime}(\mathrm{Na})=\log$ $\left([\mathrm{NaLPic}]_{\mathrm{Bz}} /\left[\mathrm{NaL}^{+}\right]\left[\mathrm{Pic}^{-}\right]\right)=1.50$ (Kudo et al., 2006); $\log K_{\mathrm{ex}, \mathrm{ip}+}(\mathrm{Ca})=\log \left(\left[\mathrm{CaLPic}^{+}\right]_{\mathrm{Bz}^{\prime}} /\left[\mathrm{CaL}^{2+}\right]\left[\mathrm{Pic}^{-}\right]\right)=\log K_{\mathrm{ex}+}$ $+\log K_{\mathrm{D}, \mathrm{L}}-\log K_{\mathrm{CaL}}=2.0_{5}$ (see Table 2). These evaluation indicates that a difference $(=0.3)$ between $\log$ $K_{\mathrm{Ca} 18 \mathrm{C} 6} K_{\text {ex, }, \mathrm{p}+}(\mathrm{Ca})$ and $\log K_{\mathrm{Na} 18 \mathrm{C} 6} K_{\text {ex,ip }}{ }^{\prime}(\mathrm{Na})\{=0.73+1.50$ (Kudo et al., 2006) $\}$ contributes to that $(=0.3)$ between $\log K_{\text {ex }}+$ and $\log K_{\text {ex }}{ }^{\prime}$. The $R_{\mathrm{IR}}$ value (=1.02 $\AA$ ) (Shannon, 1976) of $\mathrm{Na}^{+}$is close to that $(=1.00)$ of $\mathrm{Ca}^{2+}$. Thus, the $K_{\text {ex }}+$ value can be effective for a comparison of an extraction-ability of the MPic ${ }^{+}$-L extraction system with that of the M $\mathrm{M}^{\mathrm{I}} \mathrm{Pic}-\mathrm{L}$ one (Takeda, 2002; Kudo et al., 2006), because of the same dimension of such extraction constants. A similar comparison with the $\mathrm{CdPic}_{2}-18 \mathrm{C} 6$ systems has been already performed (Kudo et al., 2013). 


\section{Conclusion}

(i) The introduction of the three equilibria, expressed by $K_{\mathrm{MPic}}, K_{\mathrm{D} \text {,Pic }}$, and $K_{2}{ }^{\mathrm{Bz}}$, to the extraction model of $\mathrm{MPic}_{2}$ by $\mathrm{L}$ into Bz did not show large deviations from the reported values (Takeda \& Kato, 1979) about $K_{\text {ex }}$ and $K_{\text {ex,ip. }}$. Consequently, their values seemed not to be sensitive to the $K_{\mathrm{MPic}}$ and $K_{2}{ }^{\mathrm{Bz}}$ ones. The higher mole fractions of $\mathrm{MLPic}_{2}$ than those of MLPic in the Bz phases were verified experimentally in this regard; the smaller fractions of the ionic species can be presumed by the larger standard deviations of $K_{\mathrm{ex} \pm}$ compared with those of $K_{\mathrm{ex}}$. Also, (ii) among the extraction of alkaline-earth metal picrates by $\mathrm{L}$ employed, the evaluated $\log K_{\mathrm{D} \text {,Pic }}$ values agreed with each other. This fact suggests at least that the individual $K_{\mathrm{D}, \mathrm{A}}$ value at a fixed diluent is constant. Moreover, (iii) it was demonstrated that, regardless of the $f$ range of 0.5 to 1.8 , the composition-determination method (Takeda \& Kato, 1979; Takeda, 1979) of the extracted species MLPic ${ }_{2}$ is effective for the present extraction systems. The reason why $f$ is ineffective to $a$ was actually based on the function type of the equation, $\log \left(D_{\mathrm{M}} /\left[\mathrm{Pic}^{-}\right]^{2}\right) \approx a \log$ $[\mathrm{L}]_{\mathrm{o}}+\log \left(K_{\mathrm{ex}}^{\text {inter. }} / f\right)$.

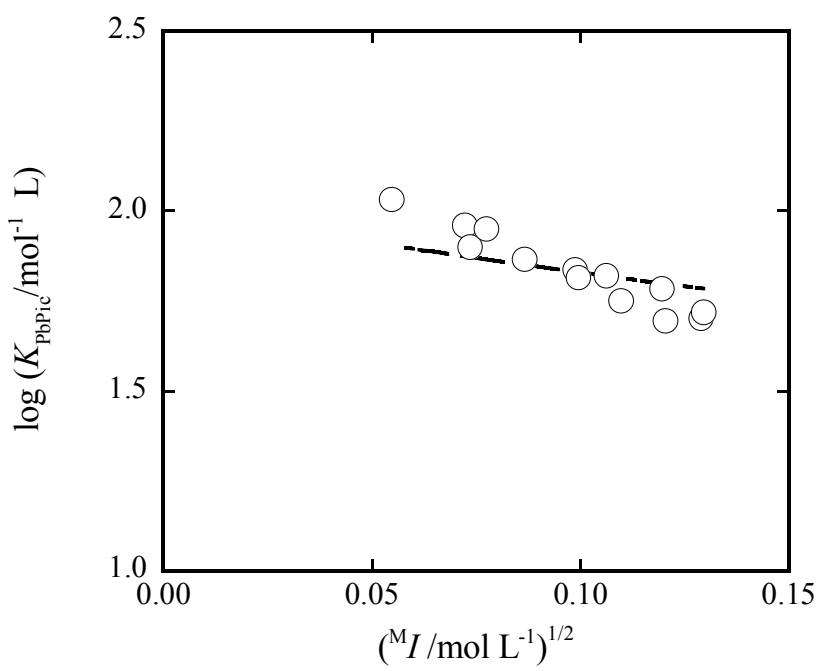

Figure 1. Plot of $\log K_{\mathrm{PbPic}}$ versus $\left({ }^{\mathrm{M}} I\right)^{1 / 2}$ for the extraction of HPic into DCE in the presence of $\mathrm{Pb}\left(\mathrm{NO}_{3}\right)_{2}$ in the aqueous phase. A broken line is a regression one with $R=0.751$ based on the equation, $\log K_{\mathrm{MA}}=\log K_{\mathrm{MA}}{ }^{0}-$ $4 \times 0.511\left\{\left({ }^{\mathrm{M}} I\right)^{1 / 2} /\left[1+\left({ }^{\mathrm{M}} I\right)^{1 / 2}\right]-0.3^{\mathrm{M}} I\right\}$ at $\mathrm{MA}^{+}=\mathrm{PbPic}^{+}$

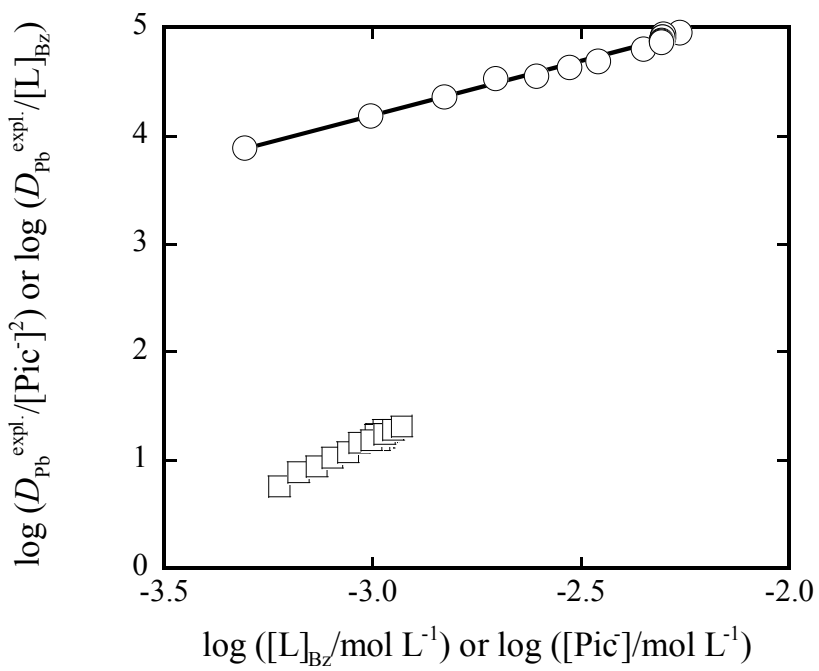

Figure 2. Plots of $\log \left(D_{\mathrm{Pb}}{ }^{\text {expl. }} /\left[\mathrm{Pic}^{-}\right]^{2}\right)$ versus $\log [\mathrm{L}]_{\mathrm{Bz}}$ and $\log \left(D_{\mathrm{Pb}}{ }^{\text {expl. }} /[\mathrm{L}]_{\mathrm{Bz}}\right)$ versus $\log \left[\mathrm{Pic}^{-}\right]$at $\mathrm{L}=\mathrm{DB} 18 \mathrm{C} 6$. The circle and square correspond to the former and the latter plots, of which the solid lines were the linear regression ones of $R=0.996$ and 0.989 , respectively 


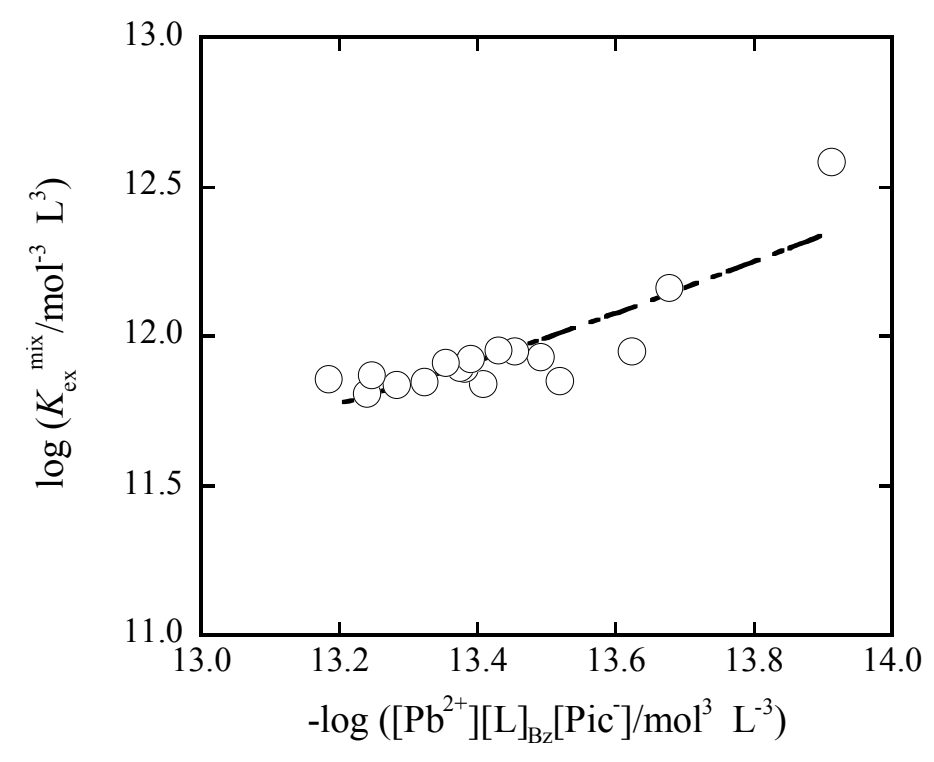

Figure 3. Plot of $\log K_{\mathrm{ex}}{ }^{\text {mix }}$ versus $-\log \left(\left[\mathrm{Pb}^{2+}\right][\mathrm{L}]_{\mathrm{Bz}}\left[\mathrm{Pic}^{-}\right]\right)$at $\mathrm{L}=18 \mathrm{C} 6$. A broken line is a non-linear regression one with $R=0.834$ based on Equation 20

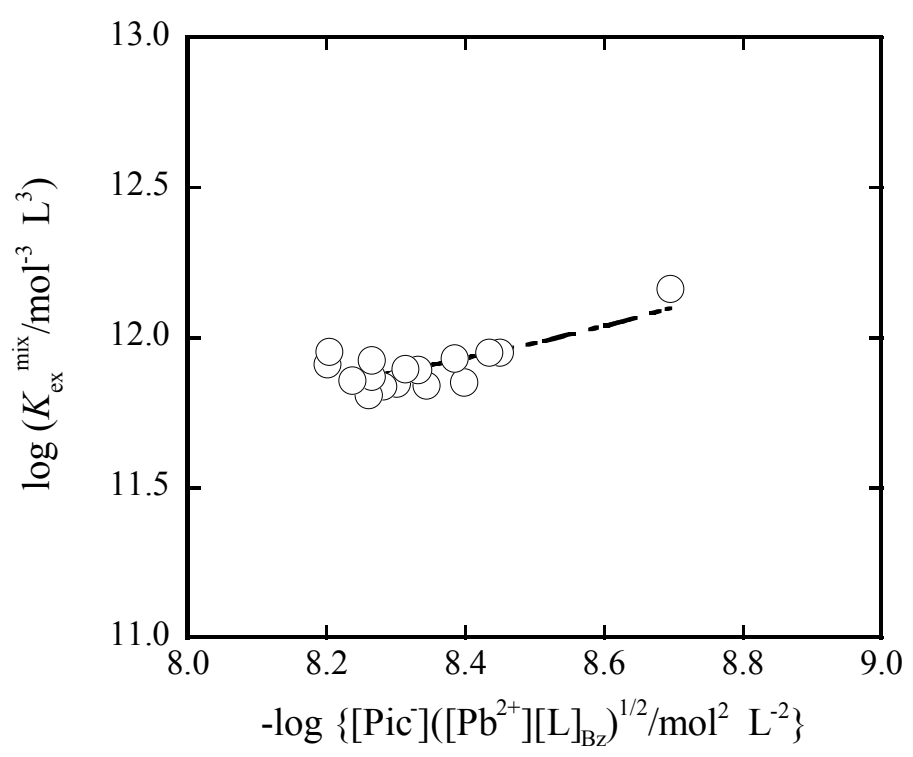

Figure 4. Plot of $\log K_{\mathrm{ex}}{ }^{\text {mix }}$ versus $-\log \left\{\left[\mathrm{Pic}^{-}\right]\left(\left[\mathrm{Pb}^{2+}\right][\mathrm{L}]_{\mathrm{Bz}}\right)^{1 / 2}\right\}$ at $\mathrm{L}=18 \mathrm{C} 6$. A broken line is a non-linear regression one with $R=0.778$ based on Equation 20a 
Table 1. Fundamental extraction and distribution constants for the MPic 2 -L extraction systems into benzene at 298 $\mathrm{K}$

\begin{tabular}{|c|c|c|c|c|c|}
\hline $\mathrm{L}$ & $\mathrm{M}$ & $I^{a} / \mathrm{mol} \mathrm{L}^{-1}$ & $\log K_{\mathrm{ex}}$ & $\log K_{\text {ex }}$ & $\log K_{\mathrm{D}, \mathrm{A}}$ \\
\hline \multirow{5}{*}{$18 \mathrm{C} 6$} & $\mathrm{Ca}$ & 0.016 & $\begin{array}{c}7.2_{7} \pm 0.2_{1} \\
7.29 \pm 0.01,7.03^{b}\end{array}$ & $0.7_{9} \pm 0.5_{0}$ & $-3.0_{5} \pm 0.2_{6}$ \\
\hline & $\mathrm{Sr}$ & 0.0043 & $\begin{array}{c}9.71 \pm 0.07 \\
9.75 \pm 0.03,9.72^{b}\end{array}$ & $2.8 \pm 2.5$ & $-3.1 \pm 1.5$ \\
\hline & $\mathrm{Ba}$ & 0.0092 & $\begin{array}{c}9.78 \pm 0.03 \\
9.77 \pm 0.02,9.79^{b}\end{array}$ & $--{ }^{c}$ & $---^{c}$ \\
\hline & $\mathrm{Cd}^{d}$ & $0.015,0.014^{e}$ & $1.98,1.95^{e}$ & -7.5 & -6.12 \\
\hline & $\mathrm{Pb}$ & 0.0030 & $\begin{array}{c}11.6_{2} \pm 0.1_{2} \\
11.2{ }_{9} \pm 0.2_{7}, 11.75^{b}\end{array}$ & $6.3_{6} \pm 0.3_{2}$ & $-1.60 \pm 0.09$ \\
\hline \multirow{3}{*}{ DB18C6 } & $\mathrm{Ca}$ & 0.016 & $\begin{array}{c}4.0_{6} \pm 0.1_{7} \\
3.9_{6} \pm 0.2_{0}, 4.01^{b}\end{array}$ & $-1.8_{3} \pm 0.7_{2}$ & $-3.1_{8} \pm 0.7_{5}$ \\
\hline & $\mathrm{Sr}$ & 0.012 & $\begin{array}{c}5.32 \pm 0.03 \\
5.32 \pm 0.06,5.38^{b}\end{array}$ & $-1.1_{8} \pm 0.4_{5}$ & $-2.9_{7} \pm 0.6_{1}$ \\
\hline & $\mathrm{Pb}$ & 0.0033 & $\begin{array}{c}7.17 \pm 0.02 \\
7.10 \pm 0.03,7.16^{b}\end{array}$ & $-0.5 \pm 1.5$ & $-3.9 \pm 1.5$ \\
\hline
\end{tabular}

${ }^{a}$ Calculated ionic strength in the aqueous phase. Here, $1 \mathrm{~L}$ was defined as $1 \mathrm{dm}^{3} .{ }^{b}$ Takeda and Kato (1979). ${ }^{c}$ Not determined because of their larger experimental errors. ${ }^{d}$ Kudo et al. (2013). ${ }^{e}$ Values evaluated by the procedure reported in Takeda and Kato (1979).

Table 2. Ion-pair extraction $\left(K_{\text {ex,ip }}\right)$ and component equilibrium constants for the $\mathrm{MPic}_{2}$-L extraction systems into benzene at $298 \mathrm{~K}$

\begin{tabular}{|c|c|c|c|c|c|c|c|}
\hline L & $\mathrm{M}$ & $\log K_{\mathrm{D}, \mathrm{L}}$ & $\log K_{\mathrm{ML}}{ }^{a}$ & $\log K_{\text {ex,ip }}$ & $\begin{array}{c}\log K_{2}^{\mathrm{Bz}} \\
\left(I_{\mathrm{o}}\right)^{b}\end{array}$ & $\begin{array}{c}\log K_{\mathrm{MA}}{ }^{c} \\
(I)^{d}\end{array}$ & $\log K_{\mathrm{HA}}{ }^{e}$ \\
\hline \multirow{5}{*}{$18 \mathrm{C} 6$} & $\mathrm{Ca}$ & & 0.48 & $5.5_{2}, 5.28^{g}$ & $\begin{array}{c}6.5 \pm 0.5 \\
\left(4.8 \times 10^{-6}\right)\end{array}$ & $\begin{array}{c}1.7 \\
(0.016)\end{array}$ & 0.48 \\
\hline & $\mathrm{Sr}$ & & 2.72 & $5.72,5.73^{g}$ & $\begin{array}{c}7.0 \pm 2.5 \\
\left(2.4 \times 10^{-6}\right)\end{array}$ & $\begin{array}{c}--{ }^{h} \\
(0.0043)\end{array}$ & 0.55 \\
\hline & $\mathrm{Ba}$ & $-1.27^{f}$ & 3.87 & $4.64,4.65^{g}$ & $--^{h}$ & $\begin{array}{c}--{ }^{h} \\
(0.0092)\end{array}$ & 0.52 \\
\hline & $\mathrm{Cd}^{i}$ & & $-0.05_{3}{ }^{j}$ & $0.76,0.73^{k}$ & $\begin{array}{c}9.5 \\
\left(8.2 \times 10^{-9}\right)\end{array}$ & $\begin{array}{c}2.0 \\
(0.015)\end{array}$ & $--^{h}$ \\
\hline & $\mathrm{Pb}$ & & 4.27 & $6.08,6.21^{g}$ & $\begin{array}{c}5.3 \pm 0.3 \\
\left(7.6 \times 10^{-6}\right)\end{array}$ & $\begin{array}{c}1.9 \\
(0.0030)\end{array}$ & 0.56 \\
\hline \multirow{3}{*}{ DB18C6 } & $\mathrm{Ca}$ & & 0.00 & $7.1_{5}, 7.09^{g}$ & $\begin{array}{c}5.9 \pm 0.7 \\
\left(2.8 \times 10^{-6}\right)\end{array}$ & $\begin{array}{c}1.7 \\
(0.016)\end{array}$ & 0.48 \\
\hline & $\mathrm{Sr}$ & $3.087^{f}$ & 1.00 & $7.41,7.46^{\mathrm{g}}$ & $\begin{array}{c}6.5 \pm 0.4 \\
\left(2.7 \times 10^{-6}\right)\end{array}$ & $\begin{array}{c}--^{h} \\
(0.012)\end{array}$ & 0.50 \\
\hline & $\mathrm{Pb}$ & & 1.89 & $8.36,8.35^{\mathrm{g}}$ & $\begin{array}{c}7.7 \pm 1.5 \\
\left(8.1 \times 10^{-7}\right)\end{array}$ & $\begin{array}{c}1.9 \\
(0.0033)\end{array}$ & 0.55 \\
\hline
\end{tabular}


${ }^{a}$ See Takeda and Kato (1979); Høiland et al. (1979); and Shchori et al. (1975). ${ }^{b}$ Calculated ionic strength/mol L ${ }^{-1}$ in the organic phases. ${ }^{c}$ Ion-pair formation constant of $\mathrm{Pb}^{2+}$ or $\mathrm{Cd}^{2+}$ with $\mathrm{Pic}^{-}$in the aqueous phase (see the text) and values evaluated from $\log K_{\mathrm{CaPic}}=1.9_{4}$ determined by potentiometry with ISE (Kudo et al., 2007) at $I \rightarrow 0$ and 298 K. ${ }^{d}$ See Table 1. ${ }^{e}$ Protonation constant of $\mathrm{Pic}^{-}$in water. ${ }^{f}$ Distribution constant of L between the aqueous and Bz phases. See Takeda, 2002. ${ }^{g}$ Takeda and Kato (1979). ${ }^{h}$ Not determined because of lack of the $K_{\mathrm{MA}}$ values. ${ }^{i}$ Kudo et al. (2013). ${ }^{j}$ Katsuta et al. (2000). ${ }^{k}$ Value calculated at $\left(I / \mathrm{mol} \mathrm{L}^{-1}\right)=0.014$. See Kudo et al. (2013) and the footnote $e$ in Table 1 .

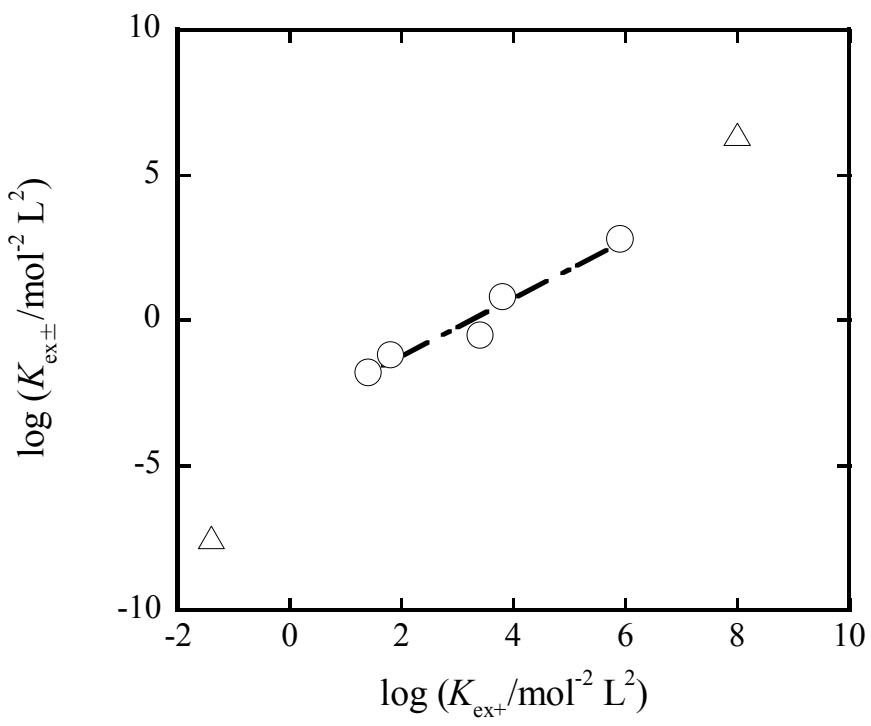

Figure 5. Plot of $\log K_{\mathrm{ex} \pm}$ versus $\log K_{\mathrm{ex}+}$ for the $\mathrm{MPic}_{2}-\mathrm{L}$ extraction systems employed. A broken line is a linear regression one based on the equation, $\log K_{\mathrm{ex} \pm}=\log K_{\mathrm{ex}+}+\log K_{\mathrm{D}, \text { Pic }}$, without the two triangles which show the points of the $\mathrm{CdPic}_{2}$ - and $\mathrm{PbPic}_{2}-18 \mathrm{C} 6$ systems

\section{References}

Frensdorff, H. K. (1971). Salt Complexes of Cyclic Polyethers. Distribution Equilibria. J. Am. Chem. Soc., 93(19), 4684-4688. http://dx.doi.org/10.1021/ja00748a006

Høiland, H., Ringseth, J. A., \& Brun, T. S. (1979). Cation-Crown Ether Complex Formation in Water. II. Alkali and Alkaline Earth Cations and 12-Crown-4, 15-Crown-5, and 18-Crown-6. J. Solution Chem., 8(11), 779-791. http://dx.doi.org/10.1007/BF00648577

Jawaid, M., \& Ingman, F. (1978). Ion-pair Extraction of $\mathrm{Na}^{+}, \mathrm{K}^{+}$, and $\mathrm{Ca}^{2+}$ with Some Organic Counter-ions and Dicyclohexyl-18-crown-6 as Adduct-forming Reagent. Talanta, 25(2), 91-95. http://dx.doi.org/10.1016/0039-9140(78)80039-3

Katsuta, S., Tsuchiya, F., \& Takeda, Y. (2000). Equilibrium studies on complexation in water and solvent extraction of zinc(II) and cadmium(II) with benzo-18-crown-6. Talanta, 51(4), 637-644. http://dx.doi.org/10.1016/S0039-9140(99)00321-5

Kielland, J. (1937). Individual Activity Coefficients of Ions in Aqueous Solutions. J. Am. Chem. Soc., 59(9), 1675-1678. http://dx.doi.org/10.1021/ja01288a032

Kikuchi, Y., \& Sakamoto, Y. (2000). Complex formation of alkali metal ions with 18-crown-6 and its derivatives in 1,2-dichloroethane. Anal. Chim. Acta, http://dx.doi.org/10.1016/S0003-2670(99)00648-0

Kolthoff, I. M., \& Chantooni Jr., M. K. (1993). Partitioning of Crown Ether Complexed Univalent Metal Dichloropicrates between Water and 1,2-Dichloroethane at $298 \mathrm{~K}$. Thermodynamic Representation. J. Chem. Eng. Data, 38(4), 556-559. http://dx.doi.org/10.1021/je00012a020

Kortüm, G., Vogel, W., \& Andrussow, K. (1961). Dissociation Constants of Organic Acids in Aqueous Solutions (p. 454). IUPAC: Section of Analytical Chemistry Commission on Electrochemical Data, Butterworths, London. 
Kudo, Y. (2013). Potentiometric Determination of Ion-Pair Formation Constants of Crown Ether-Complex Ions with Some Paring Anions in Water Using Commercial Ion-Selective Electrodes. In M. A. A. Khalid, Electrochemistry (Chapter 5, pp. 93-112). InTech, Rijeka. http://dx.doi.org/10.5772/48206

Kudo, Y., \& Takeuchi, T. (2013). Determination of Individual Distribution Constants of Alkali Metal Ions into 1,2-Dichloroethane: A Consideration for Difference between their Constants and Those Determined by Ion-Transfer Voltammetry. Chem. J., 3(1), 37-43. Retrieved from http://scientific-journals.co.uk/web_documents/3030136_alkali_metal_ions.pdf

Kudo, Y., Harashima, K., Katsuta, S., \& Takeda, Y. (2011). Solvent Extraction of Sodium Permanganate by Mono-benzo 3m-Crown- $m$ Ethers $(m=5,6)$ into 1,2-Dichloroethane and Nitrobenzene: a Method which Analyzes the Extraction System with the Polar Diluents. International J. Chem., 3(1), 99-107. Retrieved from http://ccsenet.org/journal/index.php/ijc/article/view/9235

Kudo, Y., Horiuchi, N., Katsuta, S., \& Takeda, Y. (2013). Extraction of cadmium bromide and picrate by 18-crown-6 ether into various less-polar diluents: Analysis of overall extraction equilibria based on their component equilibria with formation of their ion-pairs in water. J. Mol. Liquids, 177(1), 257-266. http://dx.doi.org/10.1016/j.molliq.2012.10.015

Kudo, Y., Katsuta, S., \& Takeda, Y. (2012). Evaluation of overall extraction constants for the crown ether-complex ions of alkali and alkaline-earth metal with counter picrate ions from water into nitrobenzene based on their $\begin{array}{llllll}\text { component } & \text { equilibrium }\end{array}$ http://dx.doi.org/10.1016/j.molliq.2012.06.003

Kudo, Y., Kobayashi, Y., Katsuta, S., \& Takeda Y. (2009). Ion-pair formation of cadmium-18-crown-6 ethers complex ions with picrate and chloride ions in water and distribution of its picrate ion-pair complex into benzene. J. Mol. Liquids, 146(1\&2), 60-65. http://dx.doi.org/10.1016/j.molliq.2009.02.004

Kudo, Y., Takeuchi, S., Kobayashi, Y., Katsuta, S., \& Takeda, Y. (2007). Potentiometric Determination of Ion-Pair Formation Constants for Cadmium, Calcium, and Cadmium-18-crown-6 Ether Derivative Complexes with a Sulfate Ion in Water. J. Chem. Eng. Data, 52(5), 1747-1752. http://dx.doi.org/10.1021/je700135j

Kudo, Y., Usami, J., Katsuta, S., \& Takeda, Y. (2006). On the difference between ion-pair formation constants of crown ether-complex ions with picrate ion in water determined by solvent extraction and by potentiometry. $J$. Mol. Liquids, 123(1), 29-37. http://dx.doi.org/10.1016/j.molliq.2005.05.003

Marcus, Y. (1994). Ion Properties (Chapter 8, pp. 117-135). New York: Marcel Dekker.

Osakai, T., \& Ebina, K. (1998). Non-Bornian Theory of the Gibbs Energy of Ion Transfer between Two Immiscible Liquids. J. Phys. Chem. B, 102(29), 5691-5698. http://dx.doi.org/10.1021/jp9814193

Rudolf, W., \& Irmer, G. (1994). Raman and Infrared Spectroscopic Investigation of Contact Ion Pair Formation in Aqueous Cadmium Sulfate Solutions. J. Solution Chem., 23(6), 663-684. http://dx.doi.org/10.1007/BF00972713

Shannon, R. D. (1976). Revised Effective Ionic Radii and Systematic Studies of Interatomic Distances in Halides and Chalcogenides. Acta Cryst., A32(5), 751-767. http://dx.doi.org/10.1107/S0567739476001551

Shchori, E., Nae, N., \& Jagur-Grodzinski, J. (1975). Stability Constants of a Series of Metal Cations with $6,7,9,10,17,18,20,21$-Octahydrodibenzo[ $b, k][1,4,10,13,16]$ hexa-oxacyclo-octadecin (Dibenzo-18-crown-6) in Aqueous Solutions. J. Chem. Soc. Dalton Trans., 2381-2386. http://dx.doi.org/10.1039/dt9750002381

Takeda, Y. (1979). The Solvent Extraction of Uni- and Bivalent Metal Picrates by Dibenzo-24-crown-8. Bull. Chem. Soc. Jpn., 52(9), 2501-2504. http://dx.doi.org/10.1246/bcsj.52.2501

Takeda, Y. (2002). Extraction of alkali metal picrates with 18-crown-6, benzo-18-crown-6, and dibenzo-18-crown-6 into various organic solvents. Elucidation of fundamental equilibria governing the extraction-ability and -selectivity. Bunseki Kagaku (Analytical Chemistry), 51(7), 515-525 (Review article in Japanese). http://dx.doi.org/10.2116/bunsekikagaku.51.515

Takeda, Y., \& Kato, H. (1979). The Solvent Extraction of Bivalent Metal Picrates by 15-Crown-5, 18-Crown-6, and Dibenzo-18-crown-6. Bull. Chem. Soc. Jpn., 52(4), 1027-1030. http://dx.doi.org/10.1246/bcsj.52.1027

Takeda, Y., \& Nishida, M. (1989). Solvent Extraction of Various Metal Picrates with Benzo-18-crown-6 into $\mathrm{CHCl}_{3}$. Bull. Chem. Soc. Jpn., 62(5), 1468-1471. http://dx.doi.org/10.1246/bcsj.62.1468 


\section{Copyrights}

Copyright for this article is retained by the author(s), with first publication rights granted to the journal.

This is an open-access article distributed under the terms and conditions of the Creative Commons Attribution license (http://creativecommons.org/licenses/by/3.0/). 